\title{
Manual Rendering Techniques in Architecture
}

\author{
Ali Dashti Shafii, Babak Monir Abbasi, and Shiva Jabari
}

\begin{abstract}
One of the most important roles of architects is the spiritization of designing by means of proper tools and techniques; this is done by a good rendering job. A good hand rendering task employs correct colorings into itself to express all the details, materials, shadows and textures. Recently, though, due to rendering software for drawing a perspective and finalizing it, a growing number of young architects and designers just hop straight onto their computers and work their ideas out. I believe they should work out hands, since nothing is better to get a point across in a design meeting than to be able to sketch it up real quick right in front of the client. Many clients are still wowed by hand drawn drawings. Hand rendering can soften drawings and even make computer generated images look more personal. In this short paper, we are trying to present some essential and delicate points in hand rendering (rendu). It would be helpful for designers who wish to improve their manual rendering techniques.
\end{abstract}

Index Terms-Architectural rendering, coloring, fast techniques, textures.

\section{INTRODUCTION}

Human being employs various expressions to communicate and convey their thoughts. The most important way of expression among humans is language, which is used in direct communication. Of course there are other means for man to relate their ideas. Art is the kind of expression which is used to conduct emotional, sensational and indirect communication of ideas.

Designing is the expression for architecture. Architecture must be designed before being built. The idea behind an architect's plan is conveyed through designing. So designing, a very important "expression", is a must in architectural education [1]. To learn architectural concepts, scholars must learn architectural expression and architectural designing. The more skilled in this field they are, the more successful in their presentation of ideas they would be. Thus, designing is very important and superior in architecture.

\section{THE IMPORTANCE OF LINE DRAWING}

Line drawing is the first and superior requirement in architectural designing process. In fact, the line drawing of an architect is the signature and personality of their architecture [2]. Their line may be fair and sensational, so becomes the outcome of the designing, like French and Italian architecture. Or it may be solid and strong line, so becomes the result, like German architecture. Architectural line is very dear and cannot be compared to line drawings of

Manuscript received June 15, 2014; revised August 13, 2014.

The authors are with the Shomal Universty of Amol, Iran (e-mail: galaxiescomet2002@yahoo.com) other arts. Never should it be oriented towards painting and caricature. The more proper statement is that line drawing of an architect must be perfect because it results to an estate, not just a painting compass!

In fact, architecture is an experimental technique of art which comes from continuous experience leading to elaboration of skills. An ideal architectural work results from a perfect observation of architectural designing. This quality of an architect is a fruit of their elaborate subtle style [3].

\section{SHADOW}

Great architectural works of art always have shadow designed as their architectural component (see Fig. 1). It is absolutely a climatic component and differs from climate to climate. As an aesthetic viewpoint, it brings climate and movement to the space of an architecture.

A scientific shadowing requires projection angle, plan, light source and its illustration. These all may not be always available. There are six reasons to apply shadow in architecture:

- Definition of form

- Definition of site

- Definition of light direction (direction of light defines the main axle in buildings cities)

- Definition of time

- Definition of different climate conditions

- Rendering of work, out of paper's white background

Designers pay a special attention to the shadow component of landscape architecture. Especially, in climate conditions that require particular conservation of human facilities [3].

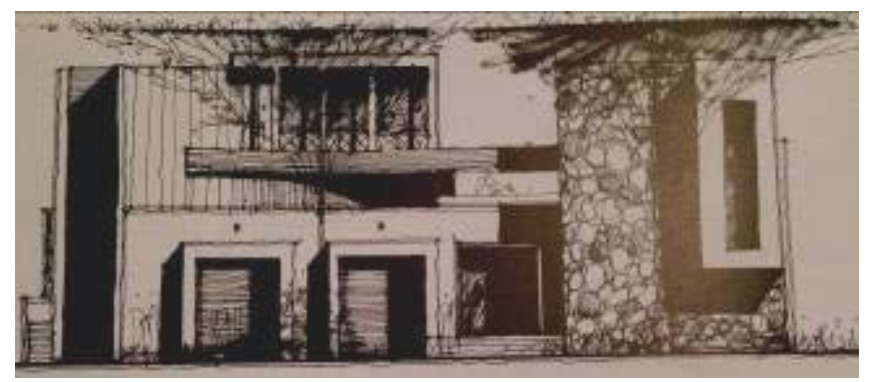

Fig. 1. Shadow.

\section{BASICS OF COLOR RENDERING}

Architectural rendering is the art of presenting architecture. Rendering can be applied to a whole building; on a plan, cross-section, facade, details etc. We usually apply rendering to spatial fixtures such as shelves, 
projections, hollows and so on [4].

To express the mood of environment, unfixed furniture is used, such as table and chair; there is no need in full coloring (see Fig. 2). A technical way of rendering is to show large or big components without coloring. Large surfaces like ground, water and sky need no specific color. To show water without the use of color, you can draw a reflection.

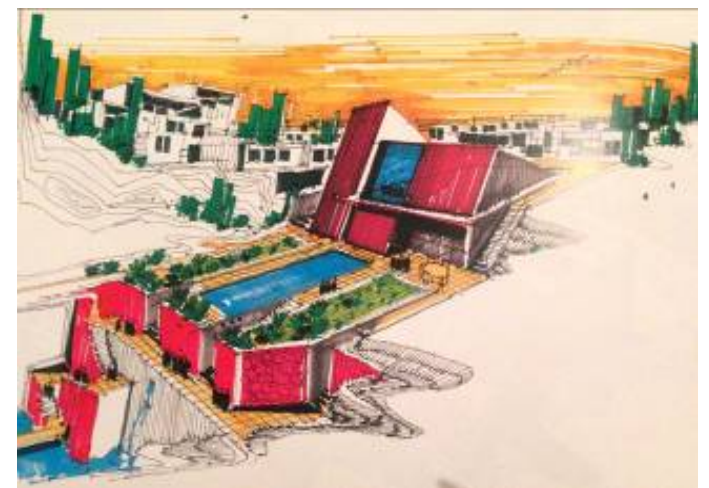

Fig. 2. Color rendering.

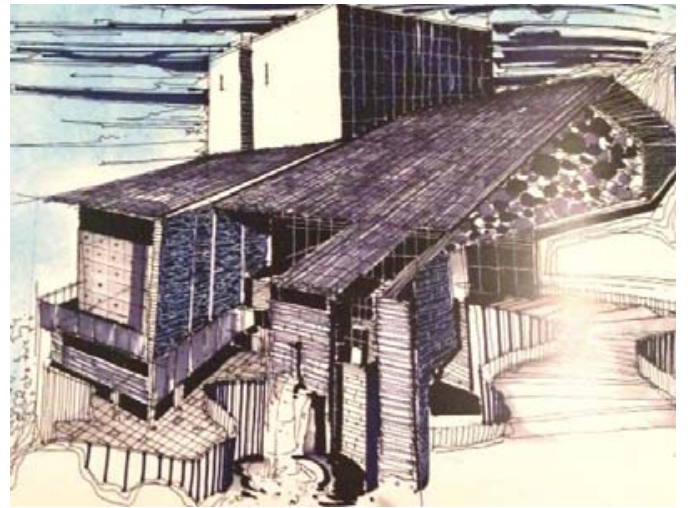

Fig. 3. Texture

First, one should imagine correctly, then apply a correct color; then architecturally render the sheet. Various techniques for rendering exist; one of the professional tools for architectural rendering is the magic marker technique.

\section{THE DifFERENCE BETWEEN ARChITECTURE AND THE ART OF PAINTING/GRAPHICS}

Lines and borders are very dear in architecture. Coloring is a means to define surfaces, the atmosphere, and the separation of planes between lines. In painting and graphics, borders are defined by colors. In fact, color acts as line for painting and graphics.

\section{TEXTURE}

There exist various solutions to present components of a building such as plan, facade, cross-section and perspective. It depends upon the architect's creativity and knowledge to choose from, e.g. coloring and collage-making [4].

A crucial part of architectural designing is to choose material and the right type of it in the right place (see Fig. 3). The most technical way of projecting these elements is to draw the building materials with regard to climate, ecosystem and time. This is superior to mere coloring of building's surfaces, because:

- it reduces the use of color

- materials are employed to functions, climate and ecosystem of the estate

- it harmonizes the estate

To draw various materials, one should be highly creative in genesis of diverse textures. This kind of creativity comes from a keen observation of materials and abstract sketching of them. Such designing knowledge and skill comes to architects as a result of drawing diverse textures which belong to different climate conditions [5].

\section{ARCHITECTURAL RENDERING TECHNIQUES}

Rendering is a technique which is done by any tool if one has the knowledge of coloring and applying the correct rules; in fact, rendering means the better presentation of one work.

Architectural rendering techniques include magic marker, water-color, colored pencil, normal pencil, charcoal, pastel, water-ink, match-ink, linear rendering, tea, bleach, dry/fresh black marker, dry colored marker, scrubber, correction fluid, white roller-ball pen, acetone...

\section{MAGIC MARKER RENDERING}

Magic marker can be used to color (paint) surfaces and planes in a rendering sheet. It also can be used to draw various textures on planes [5]. For magic marker rendering you should first outline the plan by a red pencil (because it can be mixed with marker's color), then after finishing the outline, the direction of light must be defined. In this style of rendering, you render minor surfaces instead of coloring large surfaces (e.g. glasses, water...).

Using ink-pen and white roller-ball pen to draw materials on various surfaces, makes your work more seasoned.

\section{WATER-INK}

This is the one of the most professional rendering styles; it uses different tones of a same color on different surfaces of an architecture to express it [6].

This tool can be used easily to create any texture, and to show the light and its direction. Colors are usual on a building and the use of brown, indigo and black is usual in this kind of rendering. It is important to choose and use a quality ink for this style (see Fig. 4). This rendering usually is done on large sheets on which an application of color contrasts makes the design more attractive to eyes.

Also in this technique, you should sketch by a smooth pencil, so that the sketch can be removed easily at the end and the result becomes more natural; in this manner the most beautiful skies and waters can be drawn [6].

\section{Monotone Black Rendering}

This is one of the fastest professional rendering styles (see Fig. 5). Its application is comparable to water-ink technique. Due to high color-contrast, this style is very 
attractive in terms of visuals. White roller-ball pen can be used easily to draw materials and textures on the surfaces of this rendering.

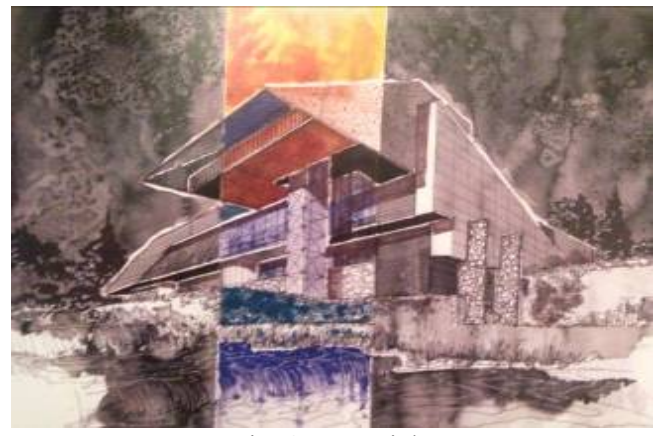

Fig. 4. Water-ink.

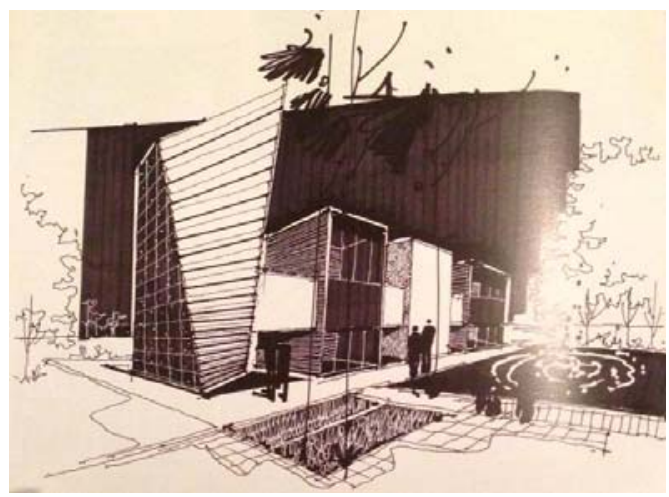

Fig. 5. Monotone black rendering.

\section{LINEAR RENDERING}

This is a fast rendering style which uses minimum tools and means at the best timing to show any target on a building architecture (see Fig. 6). Use this rendering style when defining many textures; and also when you are going to define light direction on the architecture's different layers, providing the observation of line density.

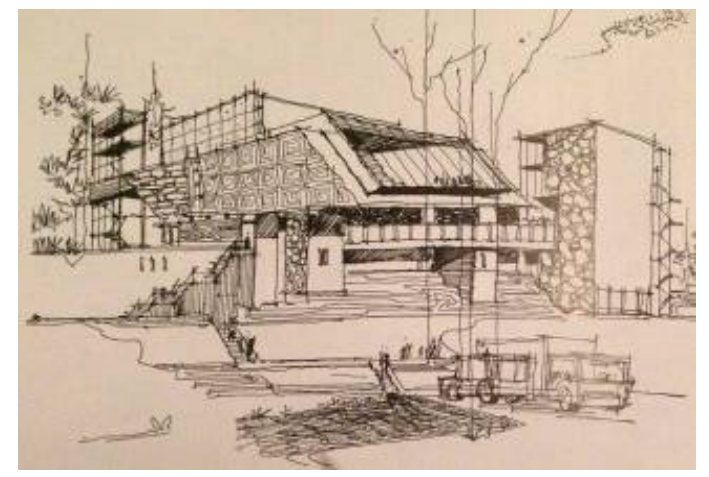

Fig. 6. Linear rendering.

\section{Monotone Rendering By Magic MARKER (EXCLUDING BLACK MARKER)}

Be audacious! Choose only one color among markers and let go of others (see Fig. 7). Draw your work by pencil or roller-ball pen, and then define the direction of light. Begin with coloring of darker layers, that is back-lighted layers, and then go through brighter layers like ceiling, floor, and front-lighted layers. Re-coloring of darker layers by the marker, gives you more intense colors. Usually, an application of scream-colors results to a more attractive work.

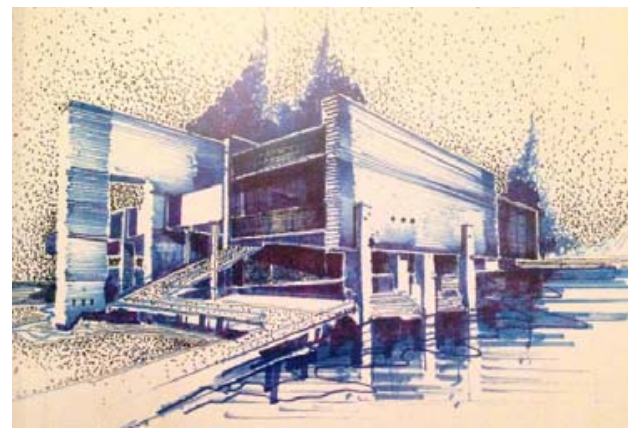

Fig. 7. Monotone rendering by magic marker.

\section{WATER-COLOR}

Due to numerous varieties of colors and facility of combining, this is one of the best rendering tools. It is used for more realistic illustrations; the quality of the water-color in use is of significant importance [6]. The more quality of the water-color be, the sooner its colors shall be dried and mat.

\section{MATCH RENDERING}

Lines in this style are porous and hollow, so they gain a specific importance. For the nature of this style, surfaces acquire a filled-blank pattern, as if the planes are made of piled match sticks [7].

For the purpose of this style, a $2 \mathrm{~mm}$ mechanical pencil is used. Match stick is stripped using a cutter. Then, as a lead, it is driven into the mechanical pencil's leadholder. A quality ink (with a specific color) is selected, then matchhead soaked with the ink gives you a kind of brush. Use it to draw your design on the sheet.

\section{BLEACH}

Bleach rendering can be operated on a colored card stock. A bleach removes paper's color and gives it a white or brighter color (see Fig. 8). Bleach can be mixed with various colors to create a specific color. Combination of bleach with different amounts of water, gives different color intensities. It is applied on the card using a brush; other tools like white ink, magic marker and roller-ball pen can be used too. To do this you should outline the primary work on a sheet (card stock) by a pencil, then begin to render it using brush and bleach [7].

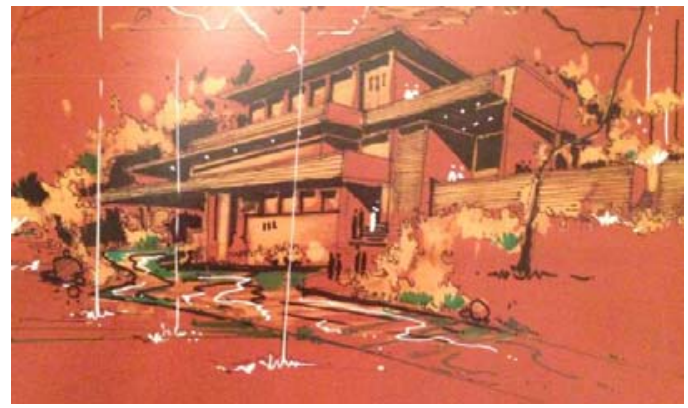

Fig. 8. Bleach rendering. 


\section{RENDERING INDOOR PERSPECTIVE}

When working on indoor perspectives, sometimes it is needed to show them in a better way or to express their spatial dimensions. Then it comes to perspective rendering. There are some techniques and tools to do this (see Fig. 9) This first step normally deals with coloring of sequences to define the depth of space. Large surfaces like floor, ceiling, and walls... should not be rendered much, because the use of color increases and the work becomes a painting.

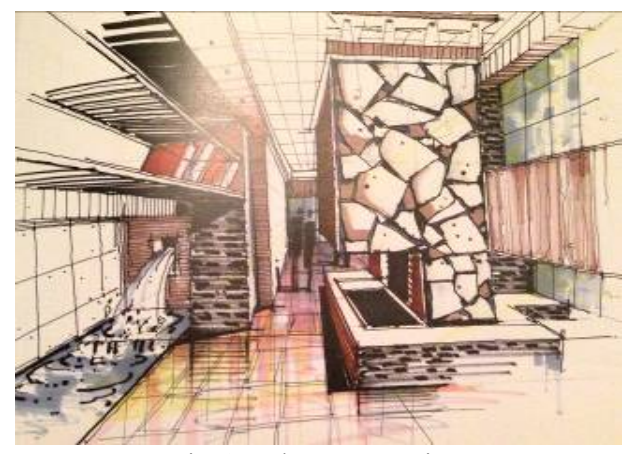

Fig. 9. Indoor perspective.

To decrease the use of color, light direction should be defined and shadows of different objects on floor and surfaces should be drawn. Some effects like reflection on the floor and glasses... give a more vivid semblance to the work.

\section{Pen, Pastel, Eye-Shadow Rendering}

To use such tools you should be very careful, firstly because they need to be fixed on paper, and secondly because the expressive power delivered by them isn't much like marker or water-color rendering [8] (see Fig. 10). They are used for fast rendering and are very handy and accessible.These tools are used merely to render sky or large surfaces in many occasions.

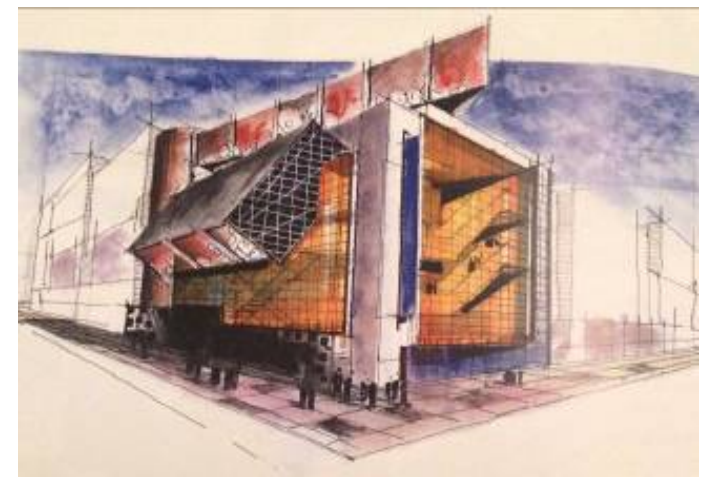

Fig. 10. Eye-shadow rendering.

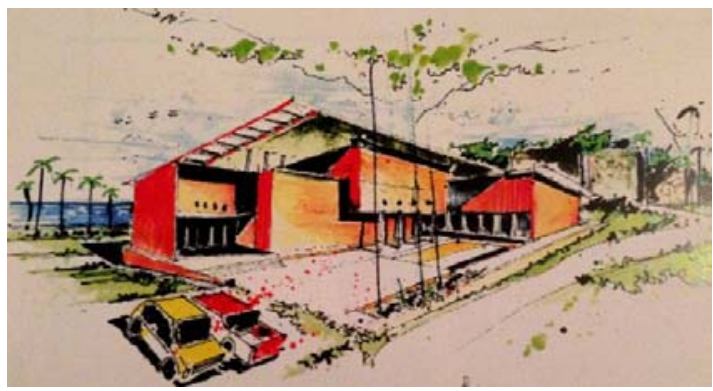

Fig. 11. Pastel rendering.
Pen among them, is slightly different, because both its powder and solid forms can be employed (see Fig. 11). though the solid form is a more professional approach. Eye shadow should be of the dry and non-rosemary kind.

\section{COMPOSITE RENDERING}

Most creative rendering works are made up of several techniques and tools that are combined and presented in an artistic fashion. To do this you should master more rendering applications and qualities (see Fig. 12). When bigger sheets are needed for a work, or it comes to diversity, you as an architect can use combination of methods [8].

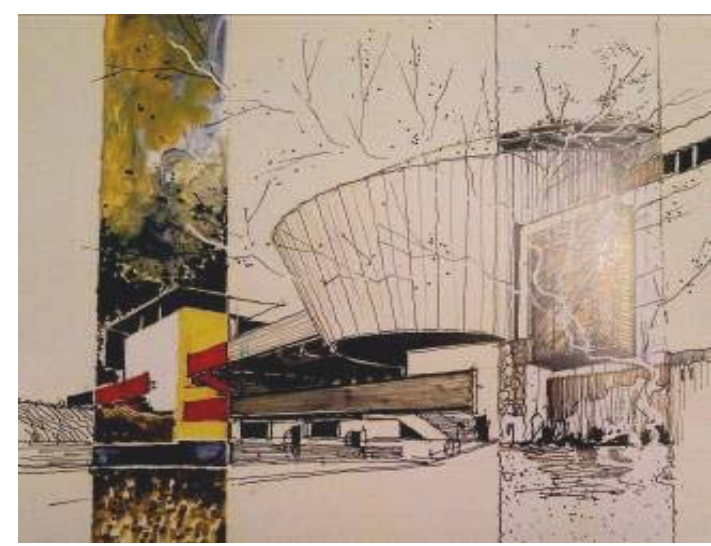

Fig. 12. Composite rendering.

\section{RENDERING OF FAÇADE}

Architectural lines are technical components, so in façade rendering you shouldn't deteriorate them when designing. Drawing of sky and trees is allowed in non-technical rendering, but for the purpose of technical rendering, drawing trees and sky - just for beatifying motives - is not appropriate [9].

Technical rendering methods in architecture include shadowing, drawing ground, drawing various textures, drawing soft shadows, inclusion of very abstract shapes of figures and trees without any color and just for scaling, defining glasses as transparent element...

\section{RENDERING OF Site Plan}

The purpose of this rendering is to define the plan in a better and more understandable fashion; usually site is colored more detailed, but on rendering a site plan, don't involve yourself with colors, because it shall take you much time. On technical rendering of plan, don't use color inside of it, let there be completely clean and white. At most, you can apply shadows to walls [9]. Render around the plan so that it project itself. For minimum use of color and increased readability, don't apply colors to both routs and spaces between; color just one of them. White segments of work leads to a more attractive and breathy product.

For site rendering you can use a monotone color or a selection of scream colors. That is personal and not obligatory to choose what types of colors. When a plan is defined as a component of sketch sheet, it should be rendered in harmony with the whole sheet and its elements. 


\section{CONCLUSION}

A good architectural rendering job which is smart and elaborate (and is considerate about lines, shadows, coloring rules, color psychology, textures, various renderings like façade, plan and site) gives spirit to your work and is pleasing to the sight of observers. Always be careful and loyal to rendering basics and rules so as to present a correct and professional rendering job.

\section{REFERENCES}

[1] E. Tayefe, How to draw architecturally 1, Elme Memar Institution, 2008, ch. 5, pp. 98-99.

[2] E. Tayefe, How to draw architecturally 2, Elme Memar Institution, 2009, ch. 2.

[3] E. Tayefe, How to draw architecturally 3, Elme Memar Institution, 2010, pp. 44-45.

[4] Q. Akrami, "The introduction section of previous book," in How to dram How to draw architecturally 3, E. Tayefe, Ed. 2010.

[5] H. R. Derakhshan, "Drawing skills tutural and its role in Architectural drawing" presented at the third National Architecture conference, Iran, March 15-16, 2013.

[6] E. K. Motlagh, "Creativing in architectural form and methods of creativing development," presented at the international conference of Civil Engineering and Architecture, Iran, 2013.

[7] S. Gheishavizade and A. R. Taghizadeh, "Use of software: a new approach in architectural drawing," presented at the first national conference on Urban Planning and Architecture across times, Iran, Tehran, 2013.
[8] M. M. Mahmoodi and K. Taghizadeh, "Information Technology and Instructional changes in Architectural engineering," presented at the National Instructional Conference on Engineering, Iran, Tehran, 1999.

[9] H. Karimi, "Teaching architectural drawing through information technology," presented at the National Conference on Urban Planning and Architecture, Iran, Tabriz, April, 2012.

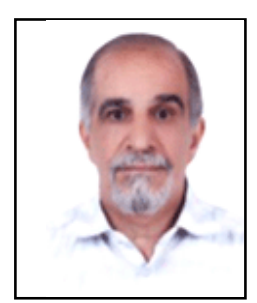

Ali Dashti Shafii was borin in Iran, 1949. He recevied his $\mathrm{PhD}$. in architecture venice, Italy in 1976, he is a professional urban planner, Venice, Italy in 1977 , he has been worked over forty years of professional architectural experience. $\mathrm{He}$ published with over 100 papers (including 40 ISI essays). An authenticated author of urban planning: the author of modern planning, building a project, fiber carbon for quake-resistance.

Babak Monir Abbasi holds master of architecture from Shabestar, Iran and he teaches at different universities such as Parand Payam Noor, Parand Islamic Azad University. Now he is working with Dr. Dashti on some project. He as an assistant.

Miss Shiva Jabari was born in Iran, 1992. She is a scholar at Shomal Univevrsity of Amol, Iran. She has good English language skills, She has worked as the corresponding author and she is Mr. Dashti's editorial assistant. She mainly works as a translator and editor. 